\section{The International AIDS Conferences from Vancouver to Bangkok: How far have we come in eight years?}

\author{
Joia S. Mukherjee ${ }^{1}$
}

1 Partners In Health, Boston, Massachusetts, United States of America; Harvard Medical School, Brigham and Woman's Hospital, Division of Social Medicine and Health Inequalities, Boston, Massachusetts, United States of America. Send correspondence to: Joia S. Mukherjee, Partners In Health, 641 Huntington Ave., Boston, Massachusetts 02115, United States of America; e-mail: jmukherjee@pih.org
In 1996 it was realized that if antiretroviral medicines were used in combination, HIV replication could be slowed significantly, allowing time for the immune system's CD4 cells to recover (1). This therapy, highly active antiretroviral therapy (HAART), or the "AIDS cocktail," restored the health of persons dying of AIDS, and persons living with HIV lived longer before succumbing to lifethreatening immune suppression. Fifteen years after the discovery of AIDS, the advent of HAART breathed hope into the disease previously considered a death sentence.

In 1996 the XIth International AIDS Conference, held in Vancouver, Canada, promised "One World, One Hope." Yet many at that conference correctly predicted that this new and expensive lifelong therapy would cause an even sharper division between two worlds-the nations of the North and the nations of the South-since access to HAART would be out of the reach of the majority of those suffering from HIV / AIDS (2). In the subsequent four years, as many as 12 million people died because they had no access to these drugs. Extending access to HAART to people from poor countries was considered too expensive and too difficult. Moreover, there was a widely held belief that treating AIDS would siphon resources away from other public health priorities, particularly programs to prevent HIV.

The International AIDS Conference in 2000, held in Durban, South Africa, was entitled "Break the Silence." That title was intended to heighten global awareness about the enormous AIDS treatment gap between rich and poor countries. The silence was indeed broken that year. Activists, including many themselves living with AIDS, raged against the lack of funding for the epidemic and the lack of access to life-saving antiretroviral therapy. The sentiment of the Durban conference and the groundwork laid by people across the sectors of health, economics, law, and human rights led to the United Nations Special Session on AIDS and to creation of the Global Fund to Fight AIDS, Tuberculosis and Malaria in 2001 (3). There was finally a funding mechanism designed to address the AIDS crisis, and the hope for a way to move toward the optimistic proclamation made in Vancouver five years before. The first grants from the Global Fund were released in late 2002, and since then bilateral aid to heavily affected countries has been increased as well.

In July of this year, eight years since the promise of "One World, One Hope," the XVth International AIDS Conference was held in Bangkok, Thailand. Its title, "Access for All," was a nod to the need to expand HIV treatment access in resource-poor settings. While antiretroviral treatment is becoming a reality for people living in developing countries, nearly all who attended the conference agreed that treatment access is not being expanded fast enough to save the lives of the nearly three million people a year who are dying from AIDS. The conference offered little in the way of scientific news: a vaccine is still years away, new drugs are few, and stopping the use of HAART, even intermittently, should be done with caution. The focus of the Bangkok AIDS conference was advocacy: advocacy for more rapid start-up and scale-up of HIV programs to meet the World Health Organization and UNAIDS' target of treating three million people with HIV with HAART by 2005 (the " 3 by 5 " initiative), advocacy for donor countries and the pharmaceutical manufacturers to allow the use of generic drugs, advocacy for the integration of prevention and treatment, and advocacy for the inclusion of marginalized groups at all levels of the global fight against AIDS. Some attendees criticized the conference for lacking scientific in- 
formation and rigor. However, to people living with HIV / AIDS and to those fighting for treatment equity, the most pressing issue in global health is "Access to All," that is, the application of the wonderful advances in HIV / AIDS treatment to people living with HIV / AIDS in resource-poor settings.

While many search for a road map to guide the implementation of expanded HIV treatment in a resource-poor setting, one country has been showing how it is done. That country is Brazil.

The importance of the data, and indeed of the Brazilian story detailed in the excellent paper by Hacker et al. (4) in this issue of Revista Panamericana de Salud Pública/Pan American Journal of Public Health, should not be underestimated. More than half of all of those treated for HIV in resource-poor settings live in Brazil. It is the only low-income or medium-income country other than Cuba that has universal access to antiretroviral therapy. In 1984, when Brazil had an interim government and was in the process of drafting a new constitution, the first cases of HIV were recognized in Latin America. Although only four cases of HIV had been detected in Brazil, a progressive movement demanded that the country develop an AIDS program. At that time, the national program was formed, and it included a human rights approach that was characterized by access to care for all. The right to HIV care was given a high priority even though it was not clear what the future would bring in terms of AIDS care and treatment or from where the funding would come.

In 1991, Brazil adopted a policy that antiretroviral drugs (at that time, zidovudine monotherapy) would be made available to all. The response of the Brazilian AIDS program to the news at the Vancouver conference of 1996 was to find a way to provide HAART on a national level. Since the health budget of Brazil would have to triple to cover the cost of the drugs alone, the decision was made that instead of buying proprietary drugs, the Government would invest in manufacturing the drugs in Brazil. Others have now begun to expand access to HIV therapy, including the Government of Botswana as well as Partners In Health, the group with which I work in Haiti (5). Brazil has demonstrated that a human rights approach, of providing free treatment to those who need it, can have a remarkable impact on the epidemic in a country.

The results of the Brazilian national AIDS program are summarized in the paper by Hacker et al. (4), which details one of the greatest success stories in the AIDS epidemic, which is now more than 20 years old. Hacker and colleagues used the Brazilian disease notification system and the country's national mortality statistics to calculate AIDS incidence and mortality rates in all the regions of Brazil. The authors assessed the firmest indicators both of prevention-incidence of new infections - and of treatment-mortality rates since the institution of universal access to HAART in Brazil.

The most important finding is that since the introduction of HAART in Brazil, not only has AIDS mortality declined but also the incidence of AIDS has fallen. In short, this bold experiment of offering free, public treatment with HAART has helped Brazil both treat the sick and slow the epidemic. These successes give confidence to people working on HIV treatment that it can be done on a large scale even in a country with income disparities such as those found in Brazil. Previous reports from Brazil and elsewhere have also demonstrated the salutary effect of antiretroviral use on the incidence of tuberculosis $(6,7)$, which is another critical aspect of the global importance of large-scale HIV programs. Argentina, Barbados, Chile, Costa Rica, Mexico, and Uruguay have promised universal access, basing their decisions on the important work done in Brazil.

However, the paper by Hacker and colleagues (4) raises two key concerns. One is the disappointing outcomes among persons living with HIV in the southern region of Brazil. The other is the poorer outcomes among women overall. The first of these concerns is thought to result from the high proportion of intravenous drug use in southern Brazil. Because intravenous drug use is a 
major risk factor of the epidemic in Thailand, issues relating to access to prevention and treatment services for drug users were central themes in the Bangkok AIDS conference. Several groups at the conference made presentations on peer education among drug users and on harm reduction programs. Thai activists protested that the lack of availability of needle exchange as well as punitive laws against drug use were deterring the fight against AIDS in their communities.

The issue of gender disparity associated with both the risk of acquiring HIV as well as access to testing and treatment was another of the major themes at the Bangkok conference. Based on the most recent UNAIDS report, which was released at the conference, women make up half of the epidemic worldwide and $57 \%$ of the epidemic in sub-Saharan Africa. In that region, the ratio of infection among women 15-24 years old as compared to their male counterparts is two to one in South Africa and four and a half to one in Kenya and Mali. There's no doubt that sexual violence, sex trafficking, and profound poverty amplify the epidemic among women. Because there are few treatment programs around the world, it is difficult to know how gender inequality will play out in the provision of care. At the Bangkok conference the Médecins Sans Frontières (Doctors Without Borders) group reported that women make up slightly more than half of the 6000 people who are being treated in their HAART programs. Nevertheless, the experience from Brazil and the increasing HIV rates among women are clear signals that the issue of gender equality should be considered of paramount importance.

The world has much to learn from the experiences of the Brazilian AIDS program. We now know that even with the provision of universal access to HIV treatment, additional attention must be paid to the most vulnerable groups, and Hacker et al. (4) indicate that this will be a future challenge for the AIDS program in Brazil. Nevertheless, the reduction in mortality and incidence of AIDS in Brazil serves as a beacon of hope that perhaps the goals of this year's International AIDS Conference can be achieved.

\section{REFERENCES}

1. Hammer SM, Squires KE, Hughes MD, Grimes JM, Demeter LM, Currier JS, et al. A controlled trial of two nucleoside analogues plus indinavir in persons with human immunodeficiency virus infection and CD4 cell counts of 200 per cubic millimeter or less. AIDS Clinical Trials Group 320 Study Team. N Engl J Med. 1997;337(11):725-33.

2. Hogg RS, Weber AE, Craib KJ, Anis AH, O'Shaughnessy MV, Schechter MT, et al. One world, one hope: the cost of providing antiretroviral therapy to all nations. AIDS. 1998;12(16):2203-9.

3. $\$ 1.3$ billion committed to global AIDS fund at close of G-8 summit. U.S. pledges extra $\$ 100$ million, work to start in January. AIDS Policy Law. 2001;16(14):1, 4.

4. Hacker MA, Petersen ML, Enriquez M, Bastos FI. Highly active antiretroviral therapy in Brazil: the challenge of universal access in a context of social inequality. Rev Panam Salud Publica. 2004;16(2):78-83.

5. Mukherjee J, Colas M, Farmer P, Léandre F, Lambert W, Raymonville M, et. al. Access to antiretroviral treatment and care: the experience of the HIV Equity Initiative, Cange, Haiti: case study. Geneva: World Health Organization; 2003. (Perspectives and Practice in Antiretroviral Treatment).

6. Badri M, Wilson D, Wood R. Effect of highly active antiretroviral therapy on incidence of tuberculosis in South Africa: a cohort study. Lancet. 2003;359(9323):2059-64.

7. Santoro-Lopes G, de Pinho AM, Harrison LH, Schechter M. Reduced risk of tuberculosis among Brazilian patients with advanced human immunodeficiency virus infection treated with highly active antiretroviral therapy. Clin Infect Dis. 2002;34(4):543-6. 